\title{
A randomized trial comparing structured and lifestyle goals in an internet-mediated walking program for people with type $\mathbf{2}$ diabetes Caroline R Richardson*1,2, Kathleen S Mehari ${ }^{1}$, Laura G McIntyre ${ }^{1}$, Adrienne W Janney ${ }^{1}$, Laurie A Fortlage ${ }^{1}$, Ananda Sen ${ }^{3}$, Victor J Strecher ${ }^{4}$ and John D Piette 2,5 $^{2}$
}

\begin{abstract}
Address: ${ }^{1}$ Department of Family Medicine, University of Michigan Health System, Ann Arbor, MI, USA, ${ }^{2} H S R \& D$ Center for Excellence, VA Health Care Medical Center, Ann Arbor, MI, USA, ${ }^{3}$ Center for Statistical Consultation and Research (CSCAR) and Department of Statistics, University of Michigan, Ann Arbor, MI, USA, ${ }^{4}$ Center for Health Communications Research, Department of Health Behavior and Health Education, University of Michigan and University of Michigan Comprehensive Cancer Center, Ann Arbor, MI, USA and ${ }^{5}$ Int Med-General Med, University of Michigan Health System and Michigan Diabetes Research and Training Center, Ann Arbor, MI, USA

Email: Caroline R Richardson* - caroli@umich.edu; Kathleen S Mehari - kathleen.mehari@hope.edu;

Laura G McIntyre - lgmac@med.umich.edu; Adrienne W Janney - pantheon@med.umich.edu; Laurie A Fortlage - lfort@umich.edu;

Ananda Sen - anandas@umich.edu; Victor J Strecher - strecher@umich.edu; John D Piette - jpiette@umich.edu

* Corresponding author
\end{abstract}

This is an Open Access article distributed under the terms of the Creative Commons Attribution License (http://creativecommons.org/licenses/by/2.0), which permits unrestricted use, distribution, and reproduction in any medium, provided the original work is properly cited.

\begin{abstract}
Background: The majority of individuals with type 2 diabetes do not exercise regularly. Pedometer-based walking interventions can help; however, pedometer-based interventions targeting only total daily accumulated steps might not yield the same health benefits as physical activity programs specifying a minimum duration and intensity of physical activity bouts.
\end{abstract}

Methods: This pilot randomized trial compared two goal-setting strategies: I) lifestyle goals targeting total daily accumulated step counts and 2) structured goals targeting bout steps defined as walking that lasts for 10 minutes or longer at a pace of at least 60 steps per minute. We sought to determine which goal-setting strategy was more effective at increasing bout steps. Participants were sedentary adults with type 2 diabetes. All participants: wore enhanced pedometers with embedded USB ports; uploaded detailed, time-stamped step-count data to a website called Stepping Up to Health; and received automated step-count feedback, automatically calculated goals, and tailored motivational messages throughout the six-week intervention. Only the automated goal calculations and step-count feedback differed between the two groups. The primary outcome of interest was increase in steps taken during the previously defined bouts of walking (lasting at least 10 minutes or longer at a pace of at least 60 steps per minute) between baseline and end of the intervention.

Results: Thirty-five participants were randomized and $30(86 \%)$ completed the pilot study. Both groups significantly increased bout steps, but there was no statistically significant difference between groups. Among study completers, bout steps increased by $1921 \pm 2729$ steps a day. Those who received lifestyle goals were more satisfied with the intervention $(p=0.006)$ and wore the pedometer more often $(p<0.001)$ than those who received structured goals. 


\begin{abstract}
Conclusion: In this six-week intervention, Lifestyle Goals group participants achieved increases in bout steps comparable to the increases seen in the Structured Goals group, representing almost a mile a day of additional moderate intensity bout activity. Pedometer-based walking programs that emphasize total accumulated step counts are more acceptable to participants and are as effective at increasing moderate intensity bouts of physical activity as programs that use structured goals.
\end{abstract}

Trial registration: NCT00I5I02I

\section{Background}

Physical activity can improve glucose control, [1-5] lower blood pressure,[1] improve blood lipid profiles, [6,7] decrease the risk of adverse cardiovascular events, [8] and decrease the risk of death among people with type 2 diabetes [9-11]. However, despite these potential health benefits, the majority of individuals with type 2 diabetes do not exercise regularly $[12,13]$. Among people with type 2 diabetes who do exercise, walking is the most popular form of physical activity [13].

Sedentary individuals with type 2 diabetes who are trying to start a walking program often use pedometers, small pager-like devices worn at the waist that count steps taken while worn. Pedometer-based walking programs have been shown to increase step counts in individuals with type 2 diabetes [14-16]. Typically, pedometer-based walking programs involve setting a daily step-count goal such as 10,000 steps per day, and participants are encouraged to accumulate steps throughout the day to reach their goals. In this lifestyle approach to physical activity, every step taken counts, and walking speed and duration of walks taken are not considered. Thus, it is possible to reach high step-count goals without performing bouts of moderate intensity physical activity.

Part of the reason pedometer-based walking programs are popular is because individuals can achieve their stepcount goals in ways that suit their lifestyle. However, some experts argue that such lifestyle programs might not result in activity that is of sufficient duration and intensity to yield improvements in cardio-respiratory fitness, and thus such programs might not yield the health benefits of more intensive structured physical activity programs [17]. Most national guidelines recommend that people perform sustained bouts of exercise of at least moderate intensity activity, rather than just accumulating activity throughout the day without any consideration of intensity or duration [18-21]. Cardio-respiratory fitness, one of the most important predictors of adverse cardiac events and mortality, [22-24] can be improved only by physical activity of duration and intensity sufficient to induce a training effect. Activity that does not reach the training threshold might yield other health benefits, but such brief and light activity is unlikely to result in improved cardio-respiratory fitness.
Fortunately, newer enhanced pedometers that incorporate built-in clocks and memory are available, allowing detailed tracking of both duration and intensity of walking, along with total steps. These enhanced pedometers can be used to track progress toward more structured goals that include a minimum duration and intensity of walking bouts into a pedometer-based walking program. The use of these enhanced pedometers paired with structured goals may increase the likelihood that those people who can successfully meet these goals improve their cardio-respiratory fitness. However, these achievements may come at a cost in terms of participant satisfaction and adherence. Little is yet known about how structured pedometer goals might affect participant's walking patterns, satisfaction and adherence to a walking program. It is important to determine whether goals can improve cardio-respiratory fitness combined with participant satisfaction and adherence in order to develop programs that can lead to long-term health benefits for people with type 2 diabetes.

The purpose of this study was to compare two different goal setting strategies in a pedometer-based walking program for people with type 2 diabetes; one employing lifestyle goals (LG) for overall steps and the other employing structured goals (SG) that emphasize greater activity intensity. The primary outcome measure was steps taken during bouts of walking that last for at least 10 minutes at an intensity of at least 60 steps per minute. Additionally, we compared participant satisfaction and adherence to each program type. We hypothesized that SG would not significantly increase steps taken during bouts of activity, but, instead, SG would decrease participant satisfaction and adherence. Therefore, overall LG would be effective both at increasing steps taking during bouts of activity, and also at increasing participant satisfaction and adherence. People who are given LG (total steps) without any criteria for duration or intensity may choose to increase their walking by going for a long walk that meets minimum intensity and duration criteria even though such activity is neither mandatory, nor encouraged by the goal.

\section{Methods Study design}

This six-week, pilot, randomized trial was conducted using an automated Internet-based intervention using uploading-enhanced pedometers for people with type 2 
diabetes. All participants wore an uploading-enhanced pedometer throughout the study period, and all had access to a personally-tailored Stepping Up to Health web page that allowed them to view: tailored motivational messages, tips about managing diabetes, automatically calculated goals, and feedback about performance toward goals. Participants were randomized to one of two groups. The LG group received goals targeting total accumulated steps, as seen in a traditional pedometer-based walking program. The SG group received goals based only on steps taken during walking bouts of at least 10 minutes with at least 60 steps per minute. We were interested primarily in whether or not an increase of steps taken during these bouts would occur (and in which group), compared to the baseline period during which no goals were set.

\section{Study population}

Participants were eligible for the study if they were at least 18 years of age and had type 2 diabetes. Eligible participants also reported regular e-mail use, and had access to an Internet-connected computer with a Windows 2000 or XP operating system and an available USB port. Participants self-reported less than 150 minutes per week of moderate physical activity at baseline and were interested in starting a walking program. Participants also had to be able to communicate in English, provide written consent, and obtain medical clearance to start a walking program from a primary care physician, endocrinologist, or cardiologist. Participants attended one face-to-face session with our study coordinator, or another member of the study staff, to complete the enrollment process. Individuals were excluded from the study if they had used a pedometer in the past 30 days or were pregnant.

\section{Recruitment}

The potential participants were identified through advertisements and referrals. Advertisements included flyers at the University of Michigan Hospital, nearby clinics, and other public locations, an ad in the local newspaper and a listing on a medical research participant recruiting website. Additionally, water bottles with the study logo and contact information were distributed to potential participants and their physicians in order to enhance recruitment.

\section{Enrollment}

All potential participants were briefly screened for eligibility over the telephone. Eligible and interested individuals were invited to attend a one-hour session to further discuss the details of the study, sign an informed consent document, and begin the enrollment process. After participants provided written informed consent, study staff assessed weight, height, and blood pressure, and participants received a medical clearance form to be completed by their physician; a password giving them access to the online baseline survey; a blinded, enhanced pedometer with an uploading USB cord; detailed instructions about uploading pedometer data to the Stepping Up to Health server; instructions for care and use of the pedometer; and a handout on walking safely specifically for people with diabetes. All participants obtained written medical clearance from a physician.

\section{Baseline data collection}

Participants were told to go about their usual activities and not to try to increase their activity during the baseline data collection phase. Participants wore the study pedometer for seven days to assess baseline step counts. During this baseline data collection phase, a sticker was placed over the pedometer face to prevent participants from seeing their step counts, and participants did not receive any goals or feedback from the Stepping Up to Health website. During the baseline week, participants also completed a detailed online survey that included questions about demographics, health history, motivations and barriers for walking, knowledge and attitudes about diabetes, and comfort with computers.

\section{Randomization}

At the end of the first week, participants who had successfully uploaded a week of baseline step-count data, completed the baseline survey, and obtained written medical clearance were randomized with equal probability into one of the two intervention groups: the LG group or the SG group. Participants received an email message informing them of their group assignment and were instructed to remove the sticker from their pedometer to unblind it. Participants were given access to a personal web page on the Stepping Up to Health website, which allowed them to view the tailored motivational messages and tips about managing diabetes. The personal web page also displayed automatically calculated goals, and feedback about performance toward goals, based on group assignment.

\section{Interventions}

Participants were asked to wear the unblinded pedometers every day, from waking to sleeping during the sixweek intervention period. Participants could read their step-count data from the pedometer display at any time throughout the day. Additionally, all participants received one new personally tailored motivational message each week on their web page, based on their individual responses to the baseline survey. The tailored motivational message algorithm was identical for the two groups, and it was developed based on aspects of the Health Belief Model (HBM) [25]. The messages highlighted perceived benefits of exercise while addressing perceived barriers and strategies to overcome those barriers. The motivational messages were therefore tailored so that the content 
specifically addressed the characteristics, motivations and barriers of the recipient.

Topics included in the tips about managing diabetes were diet and nutrition, controlling blood sugar, medication use, foot care, exercise, stress, and complications of diabetes. Figure 1 is a screen shot of a sample personalized web page.

\section{The pedometer}

The pedometer worn by participants in this study was a beta test version of the Omron HJ-720IT (Figure 2). This pedometer contains a dual-axial accelerometer, an internal clock, enough memory to store 42 days of detailed time-stamped hour-by-hour step-count data, and an embedded USB port. The mechanism and algorithms used to measure total and bout steps in these pedometers have been found to be valid and reliable in previously published studies. [26-29]. For each hour of the day, the pedometer records a time and date, total steps, bout steps, and an activity flag that indicates if the pedometer detected any movement at all during the hour. While the enhanced pedometers used are accelerometer based, they do not store or upload detailed accelerometer data or data on non-walking physical activity.
Participants were instructed to connect their enhanced pedometers to the USB port of their computer at least once a week; however, as often as they desired, they could upload detailed, hour-by-hour, time-stamped step-count data to a central computer. Data were transferred automatically from the participant's computer to a central repository.

\section{Automated goal setting and step-count feedback The LG group}

Participants randomized to receive LG were instructed to focus on total accumulated steps. The algorithm for calculating LG involved averaging the previous seven days of total step data, adding 1,200 steps to the average, and then rounding off to the nearest 100 steps. LG group participants were encouraged to focus on bout steps. A computer program translated each individual's uploaded pedometer data into individualized step-count goals and feedback messages delivered through participants' personal Stepping Up to Health web page. Feedback about progress toward goals was displayed graphically and via text messages on the participants' web page. All graphs displayed total steps; success or failure in achieving goals was based only on total step counts. LG participants received credit for any and all walking during the day, even if they did not

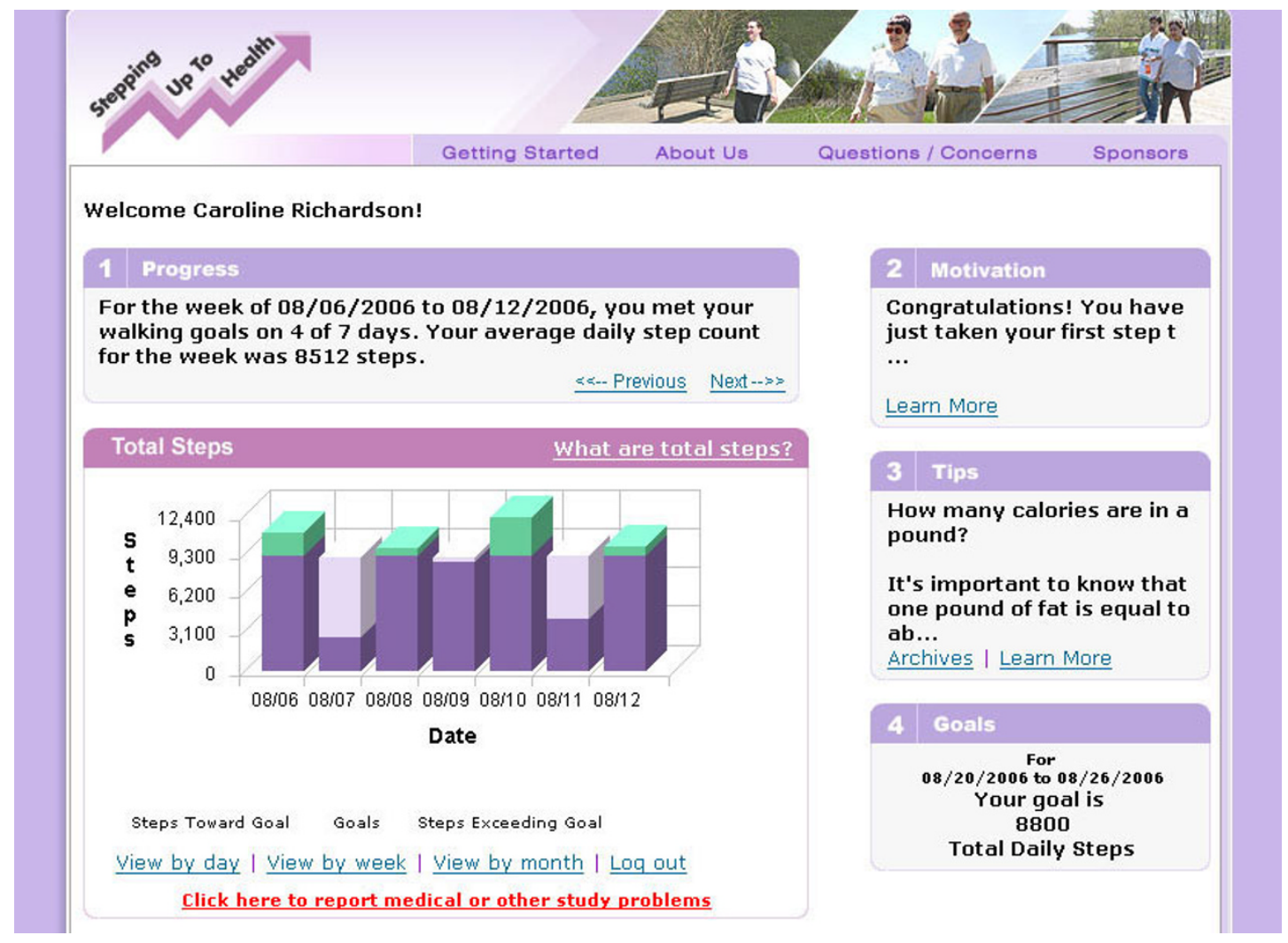

Figure I

Screen shot from the Stepping Up to Health website. 


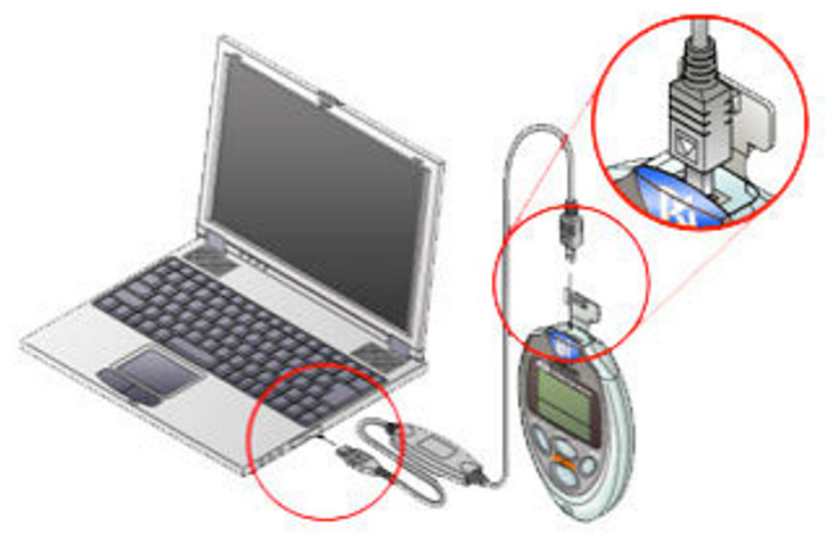

Figure 2

Omron enhanced pedometer system.

achieve minimum duration and intensity criteria. Goals were not necessarily monotonically increasing. For example, if a participant was sick, and thus had low step counts for one week, the subsequent weeks' goals might be lower than the goal for the week the participant was sick. The maximum allowable goal was 10,000 steps per day. If the calculated goals were greater than 10,000 steps per day, the goal was re-set at 10,000 steps per day.

\section{The SG group}

Participants randomized to receive SG were instructed to focus on bout steps. They were encouraged to set their pedometer to display bout steps (labeled aerobic steps on the Omron pedometers), and they were assigned weekly automatically calculated bout steps goals based only on bout-step data uploaded from the previous week. SG participants were encouraged to focus on bout steps. The algorithm for calculating SG involved averaging the previous seven days of bout step data, adding 800 steps to the average, and then rounding off to the nearest 100 steps. Feedback about progress toward goals displayed in graph and text format on the participants' web page. For SG participants, all graphs displayed only bout steps, and success or failure in achieving goals was based only on bout step counts. When SG participants did not meet minimum duration and intensity criteria, their graphs displayed zero steps. As in the LG calculations, SG participants were not necessarily monotonically increasing, and they never exceeded 10,000 steps.

Both the assigned goals and the goal increments were lower in the SG group than in the LG group (Tables 1 and 2 ). The increments for the two groups were selected based on data from our prior studies. Increments were also selected to equalize both goal difficulty and average daily total steps across the two groups. The increments for the SG group were lower because bout steps are approxi- mately $2 / 3$ of total steps for average participants. While those in the LG group got reinforcement and positive feedback every time they took a step, those in the SG group saw zeros on the pedometer display and in the graphical web-based feedback for days in which they did not complete a walk meeting minimum 10-minute bout criteria.

\section{Post intervention assessment}

At the end of the six-week intervention period, participants received an automated e-mail message asking them to complete the end-of-study activities, including: filling out a post-intervention online survey; scheduling the second session with the research staff to measure weight and blood pressure; and returning the pedometer. Participants who completed the study, and returned the enhanced pedometer, received a $\$ 25.00$ gift certificate.

\section{Statistical analysis}

Baseline characteristics were summarized using appropriate descriptive statistics. Means and standard deviations are reported for variables with a normal distribution and percentages are reported for categorical variables. Average daily bout steps and total steps were calculated for each participant, and comparisons were made between groups using unpaired t-tests. For pre-post comparisons, we used paired t-tests. For between-group comparisons of dichotomous and categorical data, including participant satisfaction data, we used chi square comparisons. Nonparametric statistics including the sign-rank test and the rank-sum test were used respectively with paired and unpaired data that were not normally distributed.

To examine individual patterns of walking, we estimated two linear regressions for each individual participant. One regression estimated the association between day of program and total steps, and the second regression estimated the association between day of program and bout steps. Days one to seven of the active intervention (after the baseline week) were dropped from each regression analysis because many participants achieved very high and unsustainable step counts on one or more days during the first week of using the pedometer. A participant was considered to have successfully increased their total steps if in the equation regressing total steps on the day of program, the estimated slope for the day of program was greater

Table I: Sample data uploaded from a participant's pedometer

\begin{tabular}{|c|c|c|c|c|c|c|c|c|}
\hline & $\begin{array}{l}\text { Sun } \\
4 / 9\end{array}$ & $\begin{array}{l}\text { Mon } \\
4 / 10\end{array}$ & $\begin{array}{l}\text { Tue } \\
4 / 11\end{array}$ & $\begin{array}{l}\text { Wed } \\
4 / 12\end{array}$ & $\begin{array}{l}\text { Thu } \\
4 / 13\end{array}$ & $\begin{array}{c}\text { Fri } \\
4 / 14\end{array}$ & $\begin{array}{c}\text { Sat } \\
4 / 15\end{array}$ & Total \\
\hline $\begin{array}{l}\text { Total } \\
\text { Steps }\end{array}$ & 3,431 & 475 & 4,328 & 5,524 & 4,930 & 5,957 & 316 & 21,530 \\
\hline $\begin{array}{l}\text { Bout } \\
\text { Steps }\end{array}$ & 0 & 0 & 1,186 & 1,099 & 3,666 & 2,364 & 0 & 8,315 \\
\hline
\end{tabular}


Table 2: A comparison of goal calculations for lifestyle and Structured Group goals.

\begin{tabular}{lcc}
\hline & $\begin{array}{c}\text { If randomized to } \\
\text { the Lifestyle Goals } \\
\text { group: }\end{array}$ & $\begin{array}{c}\text { If randomized to } \\
\text { the Structured } \\
\text { Goals group: }\end{array}$ \\
\hline $\begin{array}{l}\text { Average from week of } 4 / 9 \\
\text { to } 4 / 15\end{array}$ & 3,076 total steps & 1,188 bout steps \\
$\begin{array}{l}\text { Increment } \\
\text { New Goal for } 4 / 16 \text { to } 4 / 22 \\
- \text { rounded off to nearest }\end{array}$ & $\begin{array}{c}+, 000 \text { total steps } \\
\text { 100's }\end{array}$ & $+2,000$ bout steps \\
& & \\
\hline
\end{tabular}

than 35. This translates to an increase in total steps of 35 per day of the program, i.e. an increase of approximately 1500 steps or 0.75 miles over the six-week intervention, which is deemed clinically significant. Similarly, a participant was considered to have successfully increased their bout steps if in the equation regressing bout steps on the day of program, the estimated slope for the day of program was greater than 35 . All statistical analyses were carried out using STATA 9.0 (StataCorp, College Station, Texas).

\section{Qualitative analysis}

There were several open-ended participant satisfaction questions in the final survey. The responses to these questions were analyzed and coded using standard qualitative methods. Common themes were identified and differences in themes between groups were examined.

\section{Human subjects and safety issues}

This study was approved by the University of Michigan Institutional Review Board. All participants signed written informed consent documents.

\section{Results}

\section{Recruitment and retention}

A total of 76 participants were identified through community-based recruitment and physician referral. Of those, 62 were screened and 51 were eligible to participate in the study. Of those who were eligible, 35 completed baseline enrollment procedures and were randomized (LG group $=$ 19 , SG group $=16)$. Thirty participants $(86 \%)$ completed the entire six-week intervention. Details of recruitment and retention are reported in Figure 3 and baseline characteristics of the sample are described in Table 3. Participant ages ranged from 38 to 71 years. Five participants did not complete the program. Two participants dropped out due to lack of interest in the program, one from each group. Three participants failed to upload pedometer data at the end of the study, one from the LG group and two from the SG group.

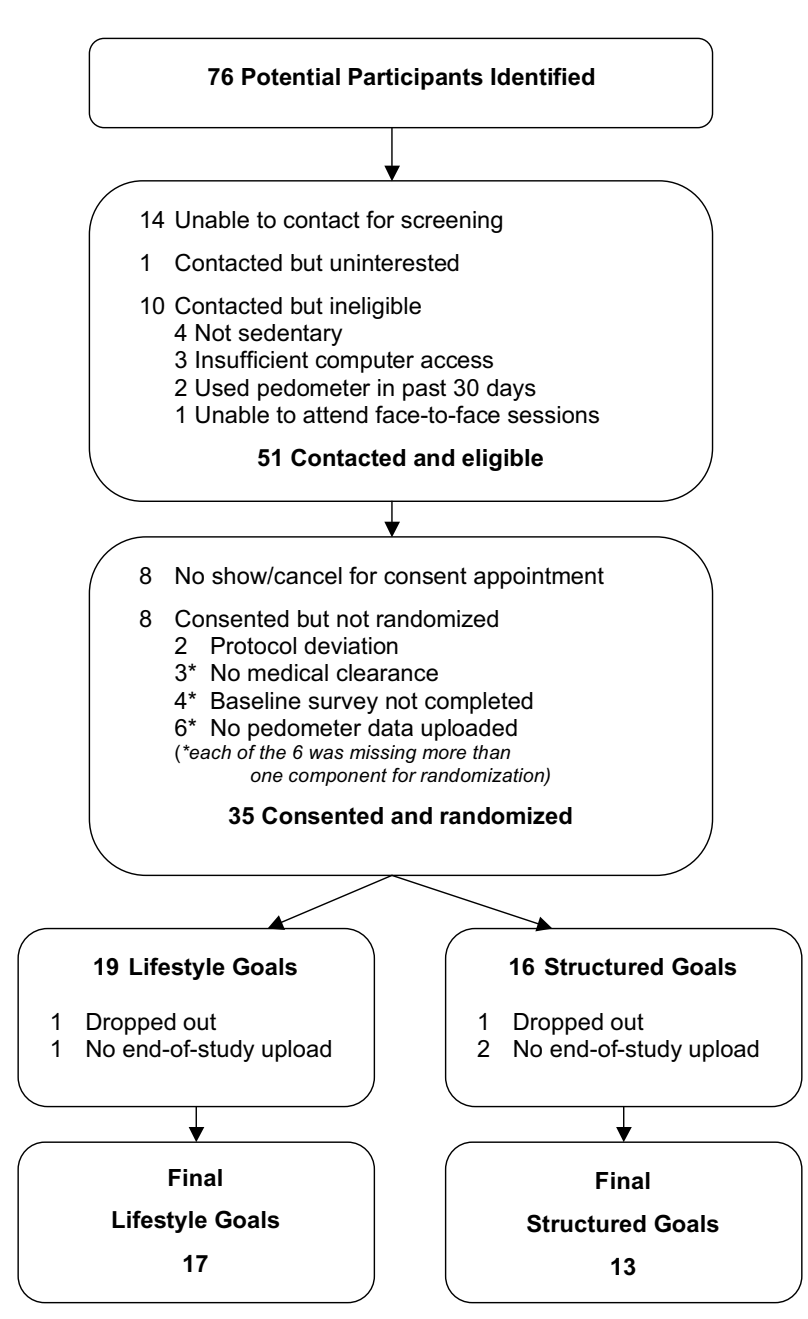

Figure 3

Recruitment and Retention.

\section{Primary outcome - average bout step counts}

Both groups significantly increased their average daily bout steps between baseline and the end of the intervention period; however, there were no between-group differences in bout step increases. Collapsing across groups, study completers increased their average daily bout steps by $1921+/-2729$ steps (paired t test $\mathrm{p}=0.0006$ ). Additionally, there was no difference in increase in total steps between those who received LG and those who received SG. Study completers increased their average daily total steps by $1938 \pm 3298$ steps (pre-post paired t-test $\mathrm{p}=$ 0.0032). For participants in both groups, most of the increase in walking was achieved during bout steps. Details of the average step-count increases are presented in Table 4.

Analysis of walking patterns for each individual participant show that approximately $44 \%$ of participants suc- 
Table 3: Baseline and demographics by randomization group.

\begin{tabular}{|c|c|c|}
\hline & $\begin{array}{l}\text { Total Step } \\
\text { Group }\end{array}$ & $\begin{array}{l}\text { Bout Step } \\
\text { Group }\end{array}$ \\
\hline $\mathbf{N}$ & 17 & 13 \\
\hline Age (SD) & $52 \pm 12$ & $53 \pm 9$ \\
\hline \multicolumn{3}{|l|}{ Sex } \\
\hline Male & $29 \%$ & $38 \%$ \\
\hline Female & $71 \%$ & $62 \%$ \\
\hline \multicolumn{3}{|l|}{ Race/Ethnicity } \\
\hline White & $76 \%$ & $77 \%$ \\
\hline Black & $18 \%$ & $8 \%$ \\
\hline Other & $6 \%$ & $15 \%$ \\
\hline Baseline Average Daily Step Count & $4,157 \pm 1,737$ & $5,171 \pm 1,769$ \\
\hline Baseline BMI & $38.6 \pm 8.2$ & $35.3 \pm 8.6$ \\
\hline \multicolumn{3}{|l|}{ Baseline Blood Pressure } \\
\hline Systolic & $133 \pm 18$ & $136 \pm 12$ \\
\hline Diastolic & $80 \pm 9$ & $82 \pm 11$ \\
\hline \multicolumn{3}{|l|}{ On Insulin } \\
\hline No & $88 \%$ & $69 \%$ \\
\hline Yes & $12 \%$ & $31 \%$ \\
\hline \multicolumn{3}{|l|}{ Income } \\
\hline$<\$ 30,000$ & $18 \%$ & $8 \%$ \\
\hline$\$ 30,000-<\$ 70,000$ & $18 \%$ & $31 \%$ \\
\hline$\geq \$ 70,000$ & $65 \%$ & $62 \%$ \\
\hline \multicolumn{3}{|l|}{ Education } \\
\hline HS diploma or GED & $6 \%$ & $8 \%$ \\
\hline Some college & $47 \%$ & $15 \%$ \\
\hline College degree & $18 \%$ & $46 \%$ \\
\hline Graduate degree & $29 \%$ & $31 \%$ \\
\hline \multicolumn{3}{|l|}{ Internet Usage (Home) } \\
\hline Never & $6 \%$ & $23 \%$ \\
\hline$\leq 4$ times per month & $12 \%$ & $8 \%$ \\
\hline Several times a week & $12 \%$ & $23 \%$ \\
\hline Almost every day & $71 \%$ & $46 \%$ \\
\hline \multicolumn{3}{|l|}{ (Work) } \\
\hline Never & $29 \%$ & $23 \%$ \\
\hline$\leq 4$ times per month & $6 \%$ & $8 \%$ \\
\hline Several times a week & $0 \%$ & $8 \%$ \\
\hline Almost every day & $65 \%$ & $62 \%$ \\
\hline
\end{tabular}

$\mathrm{SD}=$ Standard Deviation

cessfully increased their average daily steps, and 37\% successfully increased their average daily bout steps. Table 4 presents more details on this individual level analysis by group, and Figure 4 presents sample step-count graphs for individual participants in each of these response categories.

All SG participants who successfully increased their total steps did so by increasing bout steps. Seventy-five percent of LG participants who successfully increased their total steps did so by increasing bout steps. While only one participant from each of the two groups accumulated 150 minutes of bout activity during the baseline week, six participants in each group, or $40 \%$ of the participants, accumulated 150 minutes of bout activity during the final week of the program (for all participants pre-post chi $\mathrm{p}=$ $0.07)$.

\section{Participant satisfaction}

LG participants reported higher satisfaction, with 100\% reporting that they would definitely recommend the Stepping Up to Health program to friends, while only $62 \%$ of SG group would definitely recommend the program to a friend (chi sqr $\mathrm{p}=0.006$ ). In the LG group, $71 \%$ of participants found the graphs "very useful" compared to $31 \%$ in the SG group (chi sqr $\mathrm{p}=0.03$ ). In response to openended questions about satisfaction, almost all participants commented that they liked tracking their steps with the pedometers and seeing their graphs. Participants in the SG group reported being discouraged by not getting any credit for shorter walks. One SG group participant stated, "It was frustrating when I walked and walked, and it didn't count because of the 10-minute bouts."

\section{Adherence}

For 30 participants in a 42-day trial we expected 1260 days of uploaded data during the intervention. A total of 21 or $1.7 \%$ of expected days were not uploaded due to technical or logistical issues including pedometer battery failure. Additionally, 99 days had activity for less than three hours or had less than 100 steps for the day suggesting that the pedometer was not worn at all on those days. SG participants were five times as likely to fail to wear the pedometer than the LG participants (15\% versus $3 \%$, p < 0.001$)$. On those days that the pedometer was worn, the SG group wore the pedometer for fewer hours of the day on average than the LG group. The SG group wore the pedometer for a mean of 14.5 hours per day and the LG group wore the pedometer for a mean of 16.5 hours per day ( $\mathrm{t}$-test $\mathrm{p}=$ $0.038)$.

\section{Adverse events}

Participants reported twelve adverse events that were at least possibly related to the intervention. None of these were serious and most involved musculoskeletal symptoms. There were no serious adverse events, no adverse events related to coronary artery disease, and no significant differences in adverse events between groups.

\section{Discussion}

Varying the types of goals participants received did not substantially change patterns of walking among sedentary individuals with type 2 diabetes using an automated Internet-mediated walking program. In particular, SG did not result in more bout steps than LG, primarily because most of the successful LG participants chose to reach their total step goals by increasing their bout steps. The bout step increases of almost 2000 steps indicate that participants walked an average of one mile more every day at the end of the program than they were walking at the beginning of 
Table 4: Step-count results overall and by group for both total and bout steps.

\begin{tabular}{|c|c|c|c|c|}
\hline & All Participants & Lifestyle Goals Group & Structured Goals Group & p-value (between-group) \\
\hline $\mathbf{N}$ & 30 & 17 & 13 & \\
\hline \multicolumn{5}{|c|}{ Total Steps } \\
\hline Pre-Intervention & $4,596 \pm 1,794$ & $4,157 \pm 1,737$ & $5,171 \pm 1,769$ & 0.1272 \\
\hline Post-Intervention & $6,534 \pm 3,456$ & $6,279 \pm 3,306$ & $6,868 \pm 3,751$ & 0.6520 \\
\hline Change & $1,938 \pm 3,298$ & $2,122 \pm 3,179$ & $1,697 \pm 3,564$ & 0.7329 \\
\hline $\mathrm{P}$-value (pre/post) & $0.0032 *$ & $0.0142 *$ & 0.1117 & \\
\hline \multicolumn{5}{|c|}{ Bout Steps } \\
\hline Pre-Intervention & $386 \pm 691$ & $286 \pm 599$ & $516 \pm 801$ & 0.3768 \\
\hline Post-Intervention & $2,306 \pm 2,734$ & $2,070 \pm 2,814$ & $2,616 \pm 2,706$ & 0.5961 \\
\hline Change & $1,921 \pm 2,729$ & $\mathrm{I}, 783 \pm 2,74 \mathrm{I}$ & $2,101 \pm 2,815$ & 0.7583 \\
\hline $\mathrm{P}$-value (pre/post) & $0.0006^{*}$ & $0.0164^{*}$ & $0.0196^{*}$ & \\
\hline
\end{tabular}

$*=p<0.05$

Step counts expressed as Mean \pm Standard Deviation

$P$ values reflect two tailed paired t-tests

Three different responses to the Stepping Up to Health intervention
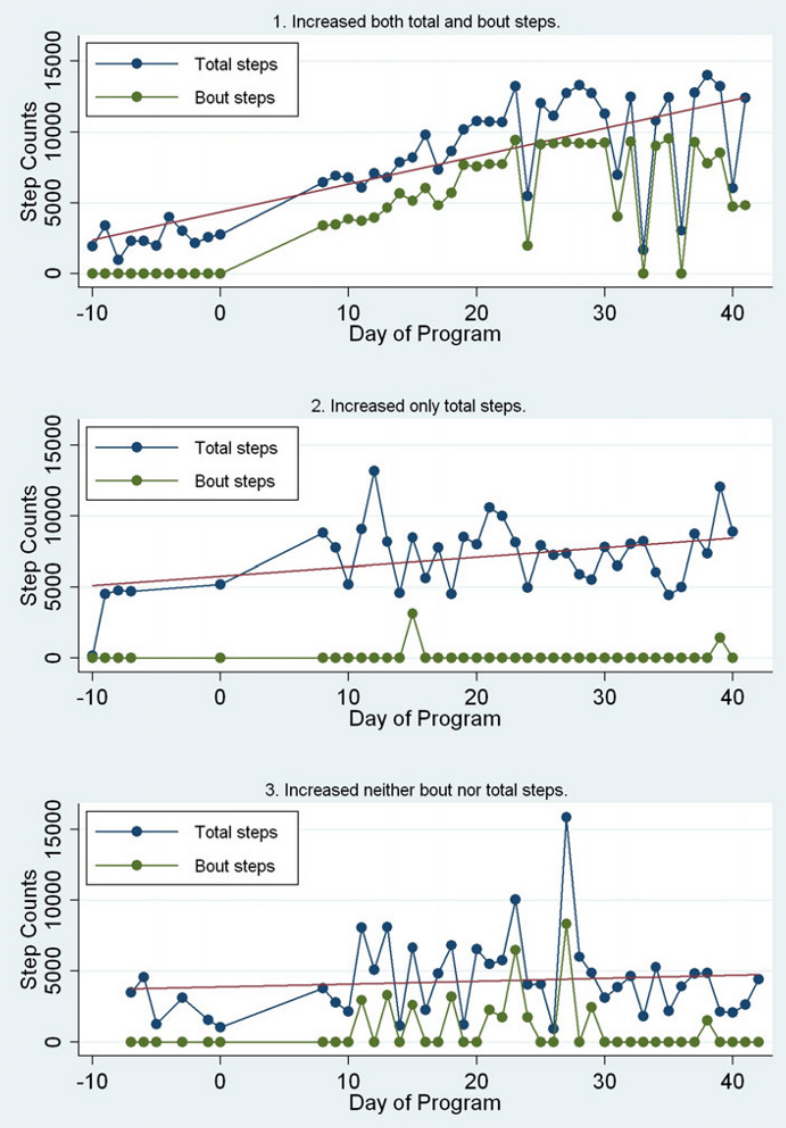

Figure 4

Walking patterns for three sample participants. the program. At a pace of 3 miles per hour, that would be an additional 20 minutes of moderate intensity activity each day. Because many of the successful participants in our LG group did increase their bouts of moderate intensity walking, presumably they gained the same health benefits that would have resulted from success in a program using structured goals targeting moderate intensity bouts of walking.

It is perhaps not surprising that LG induced increases in bout steps for many participants. With low goals, it may be easy to add in a few extra steps here and there throughout the day, rather than going on a sustained moderateintensity walk. However, as goals increase, it becomes more and more difficult to achieve success without incorporating sustained moderate-intensity bouts of walking into the day.

Participants who received structured goals were less satisfied with and less adherent to the intervention. This difference was demonstrated in participant responses to closedend satisfaction questions, in coded themes from answers to open-ended questions, and in the data on adherence to wearing the pedometer. These differences in participant satisfaction are likely to impact negatively long-term adherence to a pedometer-based walking program. While our pilot testing suggested that SG might not be as well received as $L G$, we were somewhat surprised by the magnitude of the difference in satisfaction between the two groups, particularly considering that many components of the two interventions were identical. Themes identified in response to open-ended questions suggest that the lack of continuous reinforcement for SG participants was part of what caused dissatisfaction. 
In another pedometer-based intervention study, Le Masurier (2003) found that about $49 \%$ of individuals who reached a 10,000 step target did not meet the minimum criteria of 30 minutes activity in bouts lasting for at least 10 minutes [17]. Because Le Masurier did not report baseline bout activity and because bouts of activity were measured using an accelerometer, the increase in the proportion of steps that occurred during bouts could not be determined. Goals assigned to the Stepping Up to Health participants were based on actual steps taken during the previous week, and were for the most part significantly lower than the 10,000 step goals often used for thinner, fitter, and healthier individuals. In the LG group, most participants who increased their total steps also increased their bout steps even with these relatively low LG.

This pilot study was designed to compare two versions of the Stepping Up to Health intervention, and included no true control group for evaluating the impact of Stepping Up to Health on patients' walking. Although pre-post increases in walking may reflect a Hawthorne effect, the change in step counts was substantial, and supports other evidence that pedometer-based walking programs are effective interventions for increasing physical activity among people with diabetes [17].

Despite the fact that all participants in this pilot study had type 2 diabetes, and thus were at high risk for adverse cardiovascular events, none of the participants experienced any serious or cardiovascular-related adverse events while participating in this unsupervised, unmonitored homebased walking program. This supports previous research demonstrating that moderate intensity physical activity programs are safe even in high-risk groups $[30,31]$.

The results of this pilot study must be interpreted in light of its limitations. The most important limitations of this study are the short duration of the intervention and the small number of participants. Increasing walking for only six weeks may produce transient improvements in some risk factors, but unless it is sustained over a significantly longer time, the benefits are not likely to persist. The number of participants was relatively small yet provided a sufficient sample size to detect statistically significant differences. Nonetheless, it would be reassuring to see these results replicated in a larger sample. Recruitment for this trial was limited to those who had computer and Internet access. Because of this, our results may not be generalizable to those without Internet access or to those with lower socioeconomic status. Additionally, those randomized to the structured goals group were slightly more active at baseline than those randomized to the lifestyle goals group. By calculating individually tailored step count goals based on objectively measured walking history, we minimized the effect of this baseline difference between group comparisons of step count increases. Finally, the definition of a bout step - steps taken during a walk lasting for at least 10 minutes at a pace of at least 60 steps per minute - is a relatively low-intensity threshold, approximately 2 miles per hour, and it might be too low of an intensity threshold to induce a cardio-respiratory training effect on the more fit participants in the trial.

Currently available and affordable information technology has made it possible to automate personally tailored physical activity interventions that can be delivered at low marginal cost over the Internet. However, we know little about how to design these interventions to promote sustained adherence and to optimize health outcomes. There are many more unanswered questions in the design of such complex systems. One critical question is how to help those $57 \%$ who were non-responders in this study those who did not significantly increase their total steps to start walking. Larger and longer studies are needed to provide further evidence-based optimization of automated internet-mediated walking programs.

\section{Conclusion}

Pedometer-based walking programs that emphasize total accumulated step counts are more acceptable to participants and are as effective at increasing moderate intensity bouts of physical activity as programs that use structured goals. Thus, pedometer-based walking programs that target LG (total step) rather than SG (bout step) may result in similar health benefits and in more satisfied participants.

\section{Competing interests}

The author(s) declare that they have no competing interests.

\section{Authors' contributions}

CR supervised all aspects of the study including study design, obtaining funding, intervention development, participant recruitment, data analysis and manuscript

Table 5: Individual participant walking patterns.

\begin{tabular}{lccc}
\hline & $\begin{array}{c}\text { All } \\
\text { Participants }\end{array}$ & $\begin{array}{c}\text { Lifestyle } \\
\text { Goals } \\
\text { Group }\end{array}$ & $\begin{array}{c}\text { Structured } \\
\text { Goals } \\
\text { Group }\end{array}$ \\
\hline $\mathbf{N}$ & 30 & 17 & 13 \\
$\begin{array}{l}\text { Increased both total and } \\
\text { bout steps } \\
\begin{array}{l}\text { Increased only total } \\
\text { steps }\end{array}\end{array}$ & $37 \%$ & $35 \%$ & $38 \%$ \\
$\begin{array}{l}\text { Increased neither total } \\
\text { nor bout steps }\end{array}$ & $7 \%$ & $12 \%$ & $0 \%$ \\
& $100 \%$ & $100 \%$ & $100 \%$ \\
\hline
\end{tabular}


preparation. KM and LM participated in participant recruitment, literature searches, data management and manuscript preparation. AJ, study coordinator for Stepping Up to Health, recruited subjects, reported to regulatory bodies, managed data, assisted with data cleaning, and participated in manuscript preparation. LF, a senior coordinator, wrote the protocol for the randomized controlled trial, supervised subject recruitment, ensured regulatory compliance, and participated in manuscript preparation. AS participated in the study design and performed the statistical analysis. VS participated in the study design, intervention development and manuscript preparation. JP participated in the study design, mentoring and manuscript preparation. All authors read and approved the final manuscript.

\section{Acknowledgements}

Rob Holleman assisted with data analysis for this manuscript. David A. Williams, Barbara Reed, David Goodrich and Kenneth Resnikow provided extensive feedback on manuscript drafts. This study could not have been completed without the technical expertise of Mahesh Mallia of Synapse India and Mike Nowak from the Center for Health Communications Research (CHCR) at the University of Michigan. Additionally, Janine Konkel and Shannon Considine from CHCR developed the content and complex tailoring algorithm for Stepping Up to Health's personally tailored messages. Bindiya Nandwana (Shah) assisted with portions of data collection. Medical editor Jennifer Creer assisted with revisions to this manuscript.

The study was funded by the Michigan Diabetes Research and Training Center (P60 DK020572) and the Center for Health Communications Research (P50 CA I 0I45I). Funding was also provided by Dr. Richardson's career development award from NHLBI (K23 HL075098) and Physician Faculty Scholars Program award from the Robert Wood Johnson Foundation (57408); the University of Michigan Student Biomedical Research Program (Mehari and Mclntyre); the University of Michigan Department of Family Medicine (Richardson's salary and manuscript preparation); and the VA's Health Services Research and Development Service (Richardson's and Piette's salary). Dr. Piette is a VA Research Career Scientist. Omron provided technical assistance and enhanced pedometers at a research discount. None of the funding sources played any role in study design, data analysis or interpretation, or in the decision to submit the manuscript for publication.

\section{References}

I. Agurs-Collins TD, Kumanyika SK, Ten Have TR, Adams-Campbell LL: $A$ randomized controlled trial of weight reduction and exercise for diabetes management in older African-American subjects. Diabetes Care 1997, 20(10): I503-I5II.

2. Boule NG, Haddad E, Kenny GP, Wells GA, Sigal RJ: Effects of exercise on glycemic control and body mass in type 2 diabetes mellitus: a meta-analysis of controlled clinical trials. JAMA 200I, 286( I 0): I2 | $8-1227$.

3. Larsen JJ, Dela F, Kjaer M, Galbo H: The effect of moderate exercise on postprandial glucose homeostasis in NIDDM patients. Diabetologia 1997, 40(4):447-453.

4. Paternostro-Bayles M, Wing RR, Robertson RJ: Effect of life-style activity of varying duration on glycemic control in type II diabetic women. Diabetes Care 1989, I 2(I):34-37.

5. Perseghin G, Price TB, Petersen KF, Roden M, Cline GW, Gerow K, Rothman DL, Shulman GI: Increased glucose transport-phosphorylation and muscle glycogen synthesis after exercise training in insulin-resistant subjects. N Engl J Med 1996, 335(18): | 357-1362.
6. Ligtenberg PC, Hoekstra JB, Bol E, Zonderland ML, Erkelens DW: Effects of physical training on metabolic control in elderly type 2 diabetes mellitus patients. Clin Sci (Lond) 1997, 93(2): $|27-| 35$.

7. Verity LS, Ismail AH: Effects of exercise on cardiovascular disease risk in women with NIDDM. Diabetes Res Clin Pract 1989, 6(I):27-35.

8. Hu FB, Stampfer MJ, Solomon C, Liu S, Colditz GA, Speizer FE, Willett WC, Manson JE: Physical activity and risk for cardiovascular events in diabetic women. Ann Intern Med 200I, I34(2):96-105.

9. Church TS, Cheng YJ, Earnest CP, Barlow CE, Gibbons LW, Priest EL, Blair SN: Exercise capacity and body composition as predictors of mortality among men with diabetes. Diabetes Care 2004, 27(I):83-88.

10. Gregg EW, Gerzoff RB, Caspersen CJ, Williamson DF, Narayan KM: Relationship of walking to mortality among US adults with diabetes. Arch Intern Med 2003, I63(I 2): 1440-1447.

II. Wei M, Gibbons LW, Kampert JB, Nichaman MZ, Blair SN: Low cardiorespiratory fitness and physical inactivity as predictors of mortality in men with type 2 diabetes. Ann Intern Med 2000, 132(8):605-61 I.

12. Hays LM, Clark DO: Correlates of physical activity in a sample of older adults with type 2 diabetes. Diabetes Care 1999, 22(5):706-7I2.

13. Krug LM, Haire-Joshu D, Heady SA: Exercise habits and exercise relapse in persons with non-insulin-dependent diabetes mellitus. Diabetes Educ 1991, I7(3): I85-188.

14. Tudor-Locke C, Bell RC, Myers AM, Harris SB, Ecclestone NA, Lauzon N, Rodger NW: Controlled outcome evaluation of the First Step Program: a daily physical activity intervention for individuals with type II diabetes. Int J Obes Relat Metab Disord 2004, 28(I): II3-1 I9.

15. Yamanouchi K, Shinozaki T, Chikada K, Nishikawa T, Ito K, Shimizu S, Ozawa N, Suzuki Y, Maeno H, Kato K, et al:: Daily walking combined with diet therapy is a useful means for obese NIDDM patients not only to reduce body weight but also to improve insulin sensitivity. Diabetes Care 1995, 18(6):775-778.

16. Araiza P, Hewes H, Gashetewa C, Vella CA, Burge MR: Efficacy of a pedometer-based physical activity program on parameters of diabetes control in type 2 diabetes mellitus. Metabolism 2006, 55(I 0): I382-1387.

17. Le Masurier GC, Sidman CL, Corbin CB: Accumulating $\mathbf{1 0 , 0 0 0}$ steps: does this meet current physical activity guidelines? Res $Q$ Exerc Sport 2003, 74(4):389-394.

18. US Department of Health and Human Services: Physical Activity and Health: A Report of the Surgeon General. Atlanta, GA, Center for Disease Control and Prevention, National Center for Chronic Disease Prevention and Health Promotion; 1996:278.

19. Thompson PD, Buchner D, Pina IL, Balady GJ, Williams MA, Marcus BH, Berra K, Blair SN, Costa F, Franklin B, Fletcher GF, Gordon NF, Pate RR, Rodriguez BL, Yancey AK, Wenger NK: Exercise and physical activity in the prevention and treatment of atherosclerotic cardiovascular disease: a statement from the Council on Clinical Cardiology (Subcommittee on Exercise, Rehabilitation, and Prevention) and the Council on Nutrition, Physical Activity, and Metabolism (Subcommittee on Physical Activity). Circulation 2003, 107(24):3109-3116.

20. American College of Sports Medicine Position Stand. The recommended quantity and quality of exercise for developing and maintaining cardiorespiratory and muscular fitness, and flexibility in healthy adults. Med Sci Sports Exerc 1998, 30(6):975-991.

21. Kushi LH, Byers T, Doyle C, Bandera EV, McCullough M, Gansler T, Andrews KS, Thun MJ: American Cancer Society Guidelines on Nutrition and Physical Activity for cancer prevention: reducing the risk of cancer with healthy food choices and physical activity. CA Cancer J Clin 2006, 56(5):254-8I; quiz 3I3-4.

22. Myers J, Kaykha A, George S, Abella J, Zaheer N, Lear S, Yamazaki T, Froelicher V: Fitness versus physical activity patterns in predicting mortality in men. Am J Med 2004, I I 7( I 2):912-918.

23. Laukkanen JA, Lakka TA, Rauramaa R, Kuhanen R, Venalainen JM, Salonen R, Salonen JT: Cardiovascular fitness as a predictor of mortality in men. Arch Intern Med 200I, 16I(6):825-83I.

24. Erikssen G, Liestol K, Bjornholt J, Thaulow E, Sandvik L, Erikssen J: Changes in physical fitness and changes in mortality. Lancet 1998, 352(9130):759-762. 
25. Glanz K: Behavior and Health Education: Theory, Research and Practice. 3rd edition. San Francisco, Jossey-Bass; 2002.

26. Lee M, Kim M, Bascola M, Kalck K, Bendis K, Zhu W: Position invariance of Omron-BI pedometers: a preliminary study (abstract): 13-15 October; Urbana-Champaign. ; 2005.

27. Haller J, Hasson RE, Pober DM, Freedson PS: Validation of the Omron HJ-II2 pedometer at various walking speeds (abstract): I3-15 October; Urbana-Champaign. ; 2005.

28. Hasson RE, Pober DM, Freedson PS: Evaluation of the Omron $\mathbf{H J}$ I I 2 and Yamax Digiwalker SW-70 I pedometers during variable speed walking (abstract): 13-15 October; UrbanaChampaign. ; 2005.

29. Crouter SE, Schneider PL, Bassett DR Jr.: Spring-levered versus piezo-electric pedometer accuracy in overweight and obese adults. Med Sci Sports Exerc 2005, 37(10):1673-1679.

30. Goodrich DE, Larkin AR, Lowery JC, Holleman RG, Richardson CR: Adverse events among high-risk participants in a homebased walking study: a descriptive study. The International Journal of Behavioral Nutrition and Physical Activity 2007, 4(20):

31. The LIFE Study Investigators: Effects of a Physical Activity Intervention on Measures of Physical Performance: Results of the Lifestyle Interventions and Independence for Elders Pilot (LIFE-P) Study. J Gerontol A Biol Sci Med Sci 2006, 6I(II):II57-II65.

Publish with Biomed Central and every scientist can read your work free of charge

"BioMed Central will be the most significant development for disseminating the results of biomedical research in our lifetime. "

Sir Paul Nurse, Cancer Research UK

Your research papers will be:

- available free of charge to the entire biomedical community

- peer reviewed and published immediately upon acceptance

- cited in PubMed and archived on PubMed Central

- yours - you keep the copyright

Submit your manuscript here:

http://www.biomedcentral.com/info/publishing_adv.asp
BiolMedcentral 